\title{
Polymorphism in Trypomastigotes of Trypanosoma (Megatrypanum) minasense in the Blood of Experimentally Infected Squirrel Monkey and Marmosets
}

\author{
Mariangela Ziccardi ${ }^{+}$, Ricardo Lourenço-de-Oliveira
}

Laboratório de Transmissores de Hematozoários, Departamento de Entomologia, Instituto Oswaldo Cruz, Av. Brasil 4365, 21045-900 Rio de Janeiro, RJ, Brasil

Experimental infections by Trypanosoma (Megatrypanum) minasense were performed in primates Saimiri sciureus and Callithrix penicillata - with the objective of searching for morphological variations of the blood trypomastigotes with respect to hosts and time of infection. We carried out morphological and morphometric analysis of blood trypomastigotes. Illustrations are given.

Both the squirrel monkey and marmoset became infected after the injection of blood trypomastigotes of T. minasense, although the parasitaemia were briefer in the squirrel monkey. The parasites detected in the later host were narrower and shorter than those found in the inoculated marmoset. In the marmoset, the blood stream parasites derived from culture metacyclic trypomastigotes were considerably smaller than those derived from the inoculation of infected blood.

Stronger evidence of polymorphism was found when, at the same time of infection, the blood trypomastigotes found in squirrel monkey had smaller length, body width and the distance from posterior end of the body to the kinetoplast almost four times smaller than the parasite found in the marmoset. Therefore, conflicting results on morphology and morphometry of T. minasense obtained by previous investigators could be due to polymorphism.

Key words: Trypanosoma minasense - Callithrix penicillata - Saimiri sciureus - polymorphism experimental infection

Trypanosoma (Megatrypanum) minasense Chagas has been detected in 32 species or subspecies of neotropical non-human primates, mostly in small monkeys (Cebidae), marmosets and tamarins (Callithrichidae), from Panama to southeastern Brazil (Carini 1909, Deane \& Damasceno 1961, Dunn et al. 1963, Deane 1979, Resende et al. 1994, Ziccardi \& Lourenço-de-Oliveira 1998, Deane, pers. commun.).

Several authors have noticed that blood trypomastigotes of $T$. minasense display a degree of morphological variation that makes their identification difficult or doubtful (Deane \& Damasceno 1961, Dunn et al. 1963, Ziccardi \& Lourençode-Oliveira 1998). Indeed, the range of measurable attributes of blood trypomastigotes of $T$. minasense in naturally infected monkeys and marmosets has led some authors to think that the extremes would correspond to distinct species.

${ }^{+}$Corresponding author. Fax: + 55-21-290.9339. E-mail: ziccardi@gene.dbbm.fiocruz.br

Received 27 January 1999

Accepted 3 May 1999
Rodhain (1937a) found blood trypanosomes similar to T. minasense in Saimiri sciureus, which were smaller than the typical T. minasense of marmosets (Carini 1909). Later, Rodhain (1937b, 1941), prompted by some biological differences, decided to describe the squirrel monkey's parasite as a new species, $T$. (Herpetosoma) saimirii, which recently was considered a synonym of $T$. (Tejeraia) rangeli (Ziccardi \& Lourenço-de-Oliveira 1998).

This paper describes experimental infections of both $S$. sciureus and $C$. penicillata by $T$. minasense and the morphological variations of blood trypomastigotes of this parasite with respect to hosts and time of infection. Our results indicate that conflicting data on morphology and morphometry of $T$. minasense obtained by previous investigators could be due to polymorphism.

\section{MATERIALS AND METHODS}

A young squirrel monkey S. sciureus (B9) and a young marmoset $C$. penicillata (No. 69), both born and raised in the laboratory (weight about 370 $\mathrm{g}$ and $200 \mathrm{~g}$, respectively), were inoculated intravenously (i.v.) respectively with $0.3 \mathrm{ml}$ and 0.25 $\mathrm{ml}$ of $T$. minasense infected blood obtained from a naturally infected marmoset $C$. penicillata (No. 67) caught in Felixlândia, State of Minas Gerais, Bra- 
zil. No other parasites were detected in blood smears of marmoset (No. 67) as well as in haemoculture on Novy, McNeal and Nicolle (NNN) medium supplemented with Liver Infusion Tryptose (LIT) and xenodiagnosis made with nymphs of Rhodnius prolixus. The infected marmoset (No. 67) presented 24 parasites/thick blood smears of $5 \mu$. The animals (B9 and 69) were simultaneously inoculated with the objective of following the development of infection by $T$. minasense in different hosts, as well as comparing the susceptibility of both hosts to blood trypomastigotes. The squirrel monkey was previously examined through blood smears, xenodiagnosis (with six nymphs of 3rd and 4th instar $R$. prolixus) and haemoculture (NNN + LIT) always proving negative.

The search for parasites in both inoculated primates was performed by thin and thick Giemsastained blood smears from the 7th to the 90th day post inoculation (p.i). The parasitaemia (parasites/ thick blood smears of $5 \mu \mathrm{l}$ ) was evaluated according to Earle and Perez (1932). Seventy days p.i., xenodiagnosis was made with 20 laboratory raised Aedes fluviatilis (Lutz) and Lutzomyia intermedia (Lutz and Neiva), since T. minasense multiplies in the midgut of those insects for 3-4 days after the infected blood meal (Lourenço-de-Oliveira, pers. commun.).

The same squirrel monkey (B9) was injected again (i.v.) 98 days after the first inoculation with $0.3 \mathrm{ml}$ of infected blood from the same marmoset
C. penicillata (No. 67). The blood of B9 was examined from day 7 to day 90 after the second inoculation by Giemsa-stained blood smears.

A one month old C. penicillata (No. 71), born and raised in the laboratory and negative for trypanosomes, was inoculated intraperitoneally (i.p.) and subcutaneously (s.c.) with $0.5 \mathrm{ml}$ of a 13 dayold sample (4th passage) of a culture of $T$. minasense (Ziccardi et al. 1996) which percentage of trypomastigotes was unknown. The search for parasites in the marmoset (No. 71) was performed by thin and thick Giemsa-stained blood smears from day 5 to day 30 p.i.

Trypomastigotes were sketched from blood smears and morphometric analyses were conducted according to Hoare (1972). Statistical analysis was done using a Student-t test and differences were considered to be significant when $\mathrm{p} \leq 0.01$.

\section{RESULTS}

Results show that the blood trypomastigotes of T. minasense are infective to marmosets and squirrel monkeys, although the parasitaemia seems to be briefer in the later host. T. minasense was found in the injected $S$. sciureus (B9) on days 7-14 p.i., presenting the following parasitaemia (parasites/ $5 \mu$ of blood): day 7 , one parasite; day 10, two; day 14 , one. The animal was then negative until three months p.i. One of the blood stream parasites found on the 7th day (Fig. 10) was little thinner than the typical T. minasense (e.g. Fig. 19) found in both marmosets (No. 67 and 69, respec-
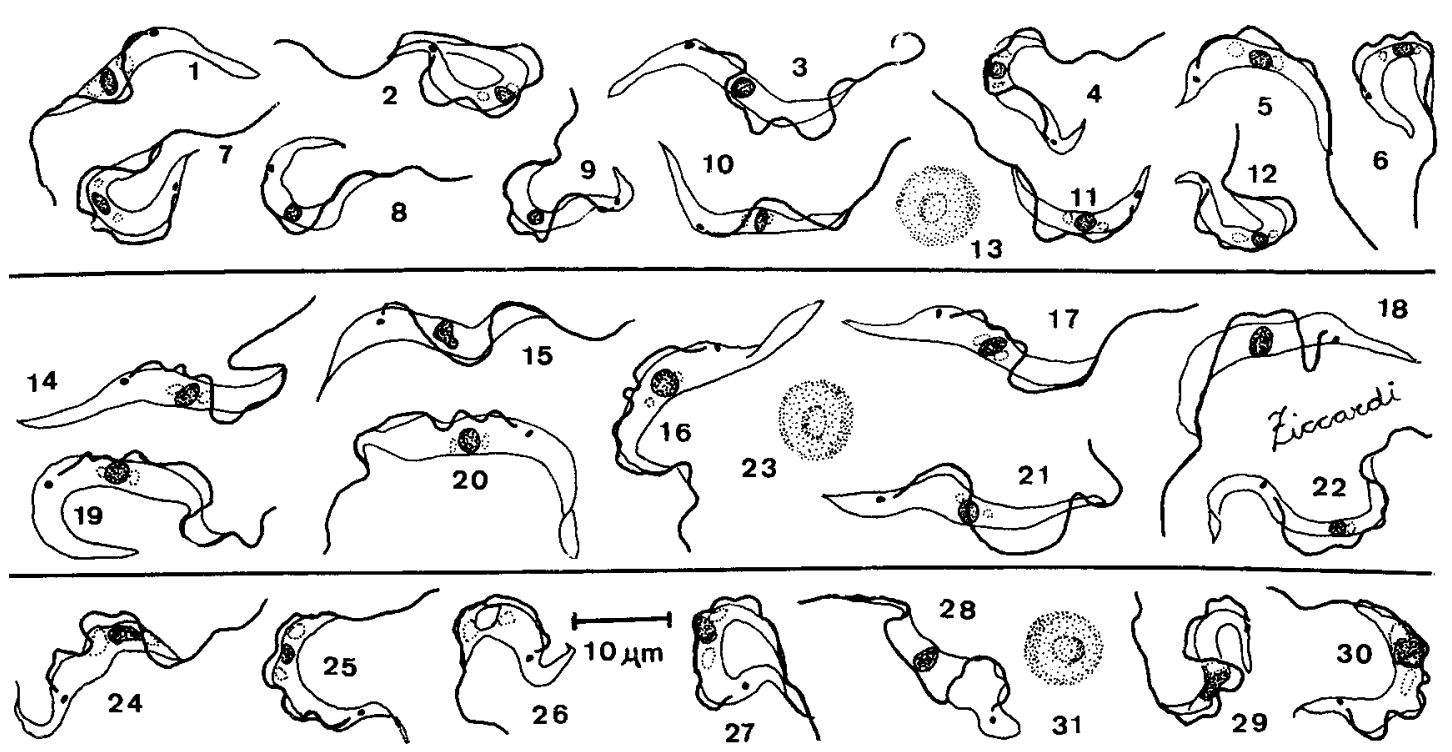

Trypanosoma minasense. Parasites found in thick blood smears. Figs 1-12: from squirrel monkey, Saimiri sciureus (B9). Figs 14 22: marmoset, Callithrix penicillata (No. 69), both experimentally infected with parasited blood. Figs 24-30: marmoset, C. penicillata (No. 71), experimentally infected with haemoculture of $T$. minasense. Figs 13, 23, 31: red blood cells shown for comparison. 
tively, naturally and experimentally infected). On the 10th day, one of the detected parasites in B9 was a typical T. minasense; a large trypomastigote with cytoplasm stained deep blue and vacuoles close to the nucleus (Fig. 3). However, another form found in B9 on the same day (10th day, Fig. 12), as well as one detected on the 14th day (Fig. 11), were quite shorter and thinner, with a pale blue stained cytoplasm, and presenting the posterior end of the body shorter and narrow. One would not identify these specimens (Fig. 12) as T. minasense, if the origin of the infection were not known. After the second inoculation $T$. minasense was seen only once in the blood of the squirrel monkey (B9): on the 7th day. Again the only detected parasite was a single thin trypomastigote (Fig. 4).

One blood trypomastigote of $T$. minasense was found in the injected marmoset (No. 69) on the 7th day p.i. Blood smears were negative on the 10th and 15th days, but became positive with a low and permanent parasitaemia from the 23rd day to the 90th (Figs 14-22), when the marmoset died of an undetermined cause. Enumeration of trypomastigotes in the blood of the marmoset (No. 69) could not be done because the required amount of blood for the Earle and Perez (1932) method was not always obtained.

The comparative analysis of measures and features of the blood trypomastigotes of $T$. minasense detected in the experimentally inoculated squirrel monkey (B9) and marmosets (Nos. 69 and 71) showed that trypanosomes found in the marmosets were larger and longer than those found in the squirrel monkey. For instance, the distance from posterior end of the body to kinetoplast (PK) of trypomastigotes of $T$. minasense derived from the inoculation of infected blood in the squirrel monkey $(\bar{X}=5.8 \mu \mathrm{m})$ is almost half that of blood parasites $(\bar{X}=10 \mu \mathrm{m})$ found in the inoculated marmoset (No. 69). The differences between these forms was also statistically significant for body length and width (Table I).

In marmosets (Nos. 69 and 71), trypomastigotes of T. minasense were generally typical forms as originally described for the species, but the measures differed statistically in three out of eight morphological characters (total length, PK, distance from nucleus to anterior end of body, Table I). Actually, the source of infection was different for each marmoset: blood stream trypomastigotes for No. 69 and metacyclic trypomastigotes from haemoculture for No. 71. The blood stream trypomastigotes derived from metacyclic trypomastigotes injected in the marmoset (No. 71) were considerably thinner and shorter; some of which (e.g. Figs 25, 29) would never be identified as $T$. minasense if the origin of the infection were not given.

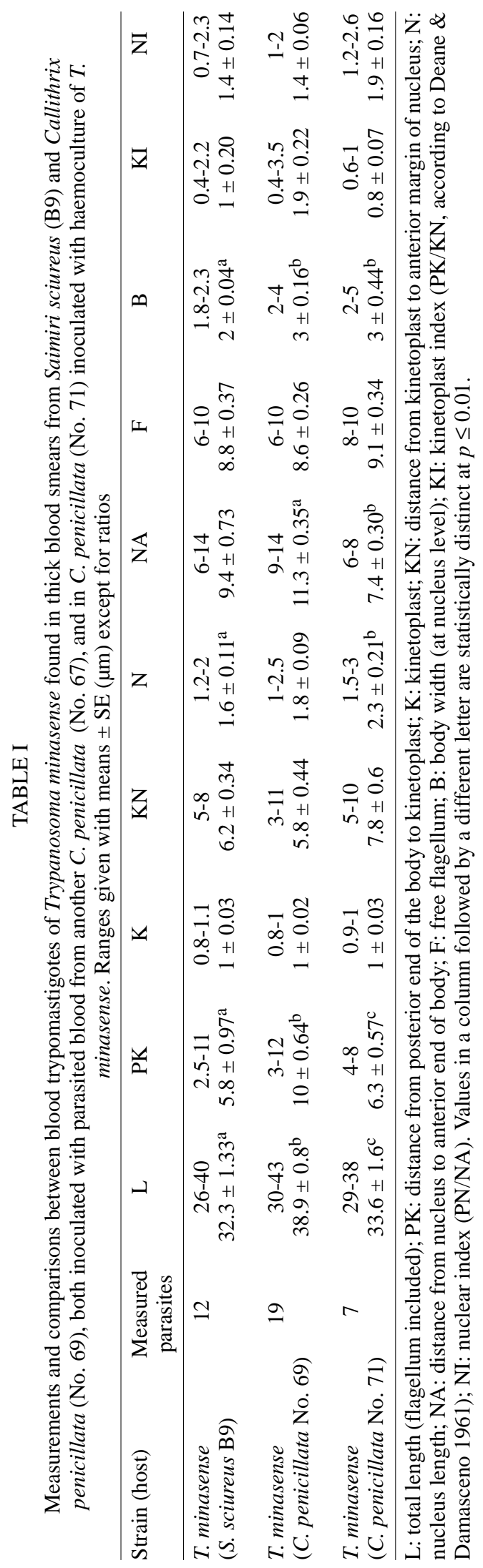




\section{DISCUSSION}

The morphological variations showed by $T$. minasense during the course of the experimental infections reported here may be due to polymorphism as previously described in other species as T. (Megatrypanum) conorhini (Deane \& Deane 1961), T. (Tejeraia) rangeli (Urdaneta-Morales \& Tejero 1992), T. (Schizotrypanum) cruzi (Brener 1979, Urdaneta-Morales 1983, Penin et al. 1996) as well as in several African trypanosome species (Miles 1970, Hoare 1972, Ormerod et al. 1974, Nantulya et al. 1978, Ormerod 1979, Barry et al. 1979, Evans \& Brightman 1980, Vickerman 1985). There is much controversy regarding the biological significance of polymorphism in the genus Trypanosoma and the mechanisms which control it. Some authors have suggested that polymorphism is related to events such as maturation, differentiation, or sexual processes in bloodstream trypomastigotes. Others believe that polymorphism is due to the mammalian host immune response (Brener 1969, 1979, Urdaneta-Morales 1983, Urdaneta-Morales \& Tejero 1992). A single trypanosome species may present variable features depending on its host, as has been observed in several amphibian trypanosomes (Bardsley \& Harmsen 1973). Hoare (1972) also suggested that morphometric variation found in T. (Nannomonas) congolense may be due to influences from different hosts. It is possible that this kind of polymorphism occurs in other mammalian trypanosomes such as T. minasense.

The evidence for host dependent polymorphism in T. minasense became stronger when we found, at the same p.i. time, blood trypomastigotes with small body length, width, and PK almost four times smaller in the inoculated squirrel monkey (B9, Fig. 32a,b, Table II).

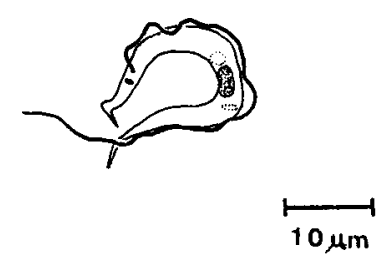

a

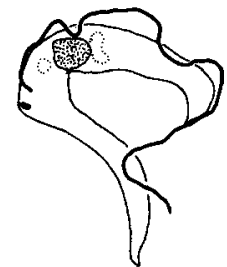

b
Trypanosoma minasense. Parasites found at the same time post inoculation (7th day) in thick blood smears. Fig. 32a: from squirrel monkey, Saimiri sciureus (B9); b: from marmoset, Callithrix penicillata (No. 69); both are experimentally infected with parasited blood.

Blood trypomastigotes of T. minasense in long term wild infected marmoset (No. 67) and squirrel monkeys (e.g. Deane \& Damasceno 1961, Ziccardi \& Lourenço-de-Oliveira 1998) are quite distinct in some morphometric characters from those reported herein in the recent infections in both the marmoset (No. 71) injected with metacyclic forms (Figs 24-30) and the squirrel monkey (B9) inoculated with blood stream parasites. In the experimental marmoset (No. 71) and squirrel monkey (B9) the blood trypomastigotes of $T$. minasense could be misidentified, for instance, with $T$. saimirii Rodhain (Ziccardi \& Lourenço-de-Oliveira 1998). The results of the present paper strengthen our hypothesis that Rodhain (1937a,b, 1941) was dealing with mixed infection ( $T$. minasense $+T$. rangeli) when he described $T$. saimirii and that $T$. saimirii is a junior synonym of $T$. rangeli (Ziccardi \& Lourenço-de-Oliveira 1998).

Conflicting results from earlier studies on the taxonomy of non human primates could be in part explained on the basis that some investigators might have measured parasites derived from dif-

\section{TABLE II}

Measurements of two blood trypomastigotes of Trypanosoma minasense found seven days post inoculation in thick blood smears from experimentally infected Callithrix penicillata (No. 69) and squirrel monkey Saimiri sciureus (B9)

\begin{tabular}{|c|c|c|c|c|c|c|c|c|c|c|c|}
\hline Strain (host) & $\begin{array}{l}\text { Measured } \\
\text { parasites }\end{array}$ & $\mathrm{L}$ & PK & $\mathrm{K}$ & $\mathrm{KN}$ & $\mathrm{N}$ & NA & $\mathrm{F}$ & $\mathrm{B}$ & $\mathrm{KI}$ & $\mathrm{NI}$ \\
\hline $\begin{array}{l}\text { T. minasense } \\
\text { (marmoset No. 69) }\end{array}$ & 1 & 39 & 13 & 1.1 & 4 & 2 & 11 & 9 & 3 & 3.3 & 1.5 \\
\hline $\begin{array}{l}\text { T. minasense } \\
\text { (squirrel monkey B9) }\end{array}$ & 1 & 28 & 3.5 & 0.8 & 7 & 1.5 & 11 & 8 & 2 & 0.5 & 1 \\
\hline
\end{tabular}

L: total length (flagellum included); PK: distance from posterior end of the body to kinetoplast; K: kinetoplast; KN: distance from kinetoplast to anterior margin of nucleus; N: nucleus length; NA: distance from nucleus to anterior end of body; F: free flagellum; B: body width (at nucleus level); KI: kinetoplast index (PK/KN, according to Deane \& Damasceno 1961); NI: nuclear index (PN/NA). 
ferent naturally infected hosts at different times in the course of the infection, which could also be simultaneously infected with distinct trypanosome species.

We concluded by stressing that workers must consider the possibility of the occurrence of both polymorphism and mixed infections before describing a new species of mammal trypanosomes.

\section{ACKNOLEGMENTS}

To Dr R Wilkerson for the critical review of the manuscript and Teresa F Silva for the aid with the illustrations.

\section{REFERENCES}

Bardsley JE, Harmsen R 1973. The Trypanosomes of Anura. Adv Parasitol 11: 1-73.

Barry JD, Le Ray D, Herbert WJ 1979. Infectivity and virulence of Trypanosoma (Trypanozoon) brucei for mice. J Comp Path 89: 465-470.

Brener Z 1969. The behaviour of slender and stout forms of Trypanosoma cruzi in the blood-stream of normal and immune mice. Ann Trop Med Parasitol 63: 215-220.

Brener Z 1979. O parasito: relações hospedeiro-parasito, p. 1-41. In Z Brener \& Z Andrade (eds), Trypanosoma cruzi e Doença de Chagas, Guanabara Koogan, Rio de Janeiro.

Carini A 1909. Über Trypanosoma minasense. Arch $f$ Schiffs Tropenhyg 13: 447-448.

Deane LM 1979. Trypanosoma cruzi and other trypanosomes in Brazilian primates, p. D9. Anais do Congresso Internacional sobre Doença de Chagas, Rio de Janeiro.

Deane LM, Damasceno RG 1961. Tripanosomídeos de mamíferos da região amazônica II. Tripanosomas de macacos da Zona do Salgado, Estado do Pará. Rev Inst Med Trop São Paulo 3: 61-70.

Deane MP, Deane LM 1961. Studies on the life-cycle of Trypanosoma conorhini. In vitro cultivation of the bloodstream trypanosomes. Rev Inst Med Trop São Paulo 3: 149-160.

Dunn FL, Lambrecht FL, Du Plessis R 1963. Trypanosomes of South American monkeys and marmosets. Am J Trop Med Hyg 12: 524-534.

Earle WC, Perez M 1932. Enumeration of parasites in the blood of malarial patients. J Lab Clin Med 17: 1124-1130.

Evans DA, Brightman CAJ 1980. Pleomorphism and the problem of recrudescent parasitaemia following treatment with salicylhydroxamic acid (SHAM) in African trypanosomiasis. Trans R Soc Trop Med Hyg
74: 601-604.

Hoare CA 1972. The Trypanosomes of Mammals, Blackwell Scientific Publication, Oxford, 749 pp.

Miles MA 1970. Pleomorphism demonstrated in a clone of an akinetoplastic strain of Trypanosoma evansi. Trans R Soc Trop Med Hyg 64: 471.

Nantulya VM, Doyle JJ, Jenni L 1978. Studies on Trypanosoma (Nannomonas) congolense I. On the morphological appearance of the parasite in the mouse. Acta Tropica 35: 329-337.

Ormerod WE 1979. Development of Trypanosoma bruce $i$ in the mammalian host, p. 339-393. In WHR Lumsden, DA Evans (eds), The Biology of Kinetoplastida, Academic Press, New York.

Ormerod WE, Venkatesan S, Carpenter RG 1974. The effect of immune inhibition on pleomorphism in Trypanosoma brucei rhodesiense. Parasitology 68: 355367.

Penin P, Gamallo C, Diego JA 1996. Biological comparison between three clones of Trypanosoma cruzi and the strain of origin (Bolivia) with reference to clonal evolution studies. Mem Inst Oswaldo Cruz 91: 285-291.

Resende DM, Pereira LH, Lôbo A 1994. Long-term patency of blood parasitism by Trypanosoma minasense and Microfilariae in Callithrix penicillata marmosets (Primates, Callitrichidae), caught in wild and maintained in captivity. Mem Inst Oswaldo Cruz 89: $127-128$.

Rodhain J 1937a. Notes sur Trypanosoma minasense Chagas. C R Soc Bio 125: 1034-1036.

Rodhain J 1937b. Notes sur Trypanosoma minasense Chagas. Evolution du trypanosome du Saimiri chez divers arthropodes. C R Soc Bio 126: 69-72.

Rodhain J 1941. Notes sur Trypanosoma minasense Chagas. Identité spécifique du trypanosome du Saimiri: Chrysothrix sciureus. Acta Biol Belg 1: 187192.

Urdaneta-Morales MS 1983. Pleomorphism in trypomastigotes of Trypanosoma cruzi from blood and cell culture. Tropenmed Parasit 34: 225-228.

Urdaneta-Morales MS, Tejero F 1992. Trypanosoma rangeli (Tejera, 1920): observations upon pleomorphism. Mem Inst Oswaldo Cruz 87: 511-516.

Vickerman K 1985. Developmental cycles and biology of pathogenic trypanosomes. Bri Med Bull 41: 105-114.

Ziccardi M, Lourenço-de-Oliveira R 1998. Morphological features of trypanosomes from squirrel monkeys from the Brazilian Amazon. Mem Inst Oswaldo Cruz, 93: 45-55.

Ziccardi M, Lourenço-de-Oliveira R, Nogueira R 1996. The haemoculture of Trypanosoma minasense Chagas, 1908. Mem Inst Oswaldo Cruz 91: 501-505. 
